\title{
UJI KEMAMPUAN ISOLAT JAMUR Trichoderma spp. SEBAGAI ANTAGONIS Ganoderma boninense DAN Plant Growth Promoting Fungi (PGPF)
}

\author{
ABILITY TEST OF Trichoderma spp. ISOLATE AS ANTAGONIST OF \\ Ganoderma boninense AND PLANT GROWTH PROMOTING FUNGI (PGPF)
}

\author{
Yohan Yogaswara*, Radix Suharjo, Suskandini Ratih dan Cipta Ginting \\ Jurusan Agroteknologi, Fakultas Pertanian, Universitas Lampung, \\ Jl. Prof. Soemantri Brodjonegoro, No. 1 Bandar Lampung 35145 \\ *E-mail:yogaswarayohan@gmail.com
}

\begin{abstract}
This study aims to determine the ability of Trichoderma spp. Isolate that collection of Biotechnology Laboratory, Faculty of Agriculture, University of Lampung as an antagonist against Ganoderma boninense and also its ability as a Plant Growth Promoting Fungi (PGPF). Testing of Trichoderma spp. as an antagonist include tests for growth, spore density, and viability. Testing of Trichoderma spp. as PGPF (Plant Growth Promoting Fungi) using cucumber plants F1 variety to obtain the ability of Trichoderma spp. in improving cucumber plant performance. The data obtained were analyzed by analysis of variance and further tested DMRT (Duncan's Multiple Range Test) at 5\% level. The results showed that all isolates of Trichoderma spp. can act as an antagonist against Ganoderma boninense. In the PGPF test, there were 3 isolates of Trichoderma spp. which showed the best performance as a plant growth promoting namely L1, L5 and L10 isolates. In addition, these isolates also have good antagonistic.
\end{abstract}

Keywords: antagonists, Ganoderma boninense, Plant Growth Promoting Fungi, Trichoderma spp

\begin{abstract}
ABSTRAK
Penelitian ini bertujuan untuk mengetahui kemampuan Trichoderma spp. Koleksi Laboratorium Bioteknologi Fakultas Pertanian Universitas Lampung sebagai antagonis terhadap jamur Ganoderma boninense dan juga kemampuannya sebagai Plant Growth Promoting Fungi (PGPF). Pengujian jamur Trichoderma spp. sebagai antagonis meliputi uji pertumbuhan, kerapatan spora, dan viabilitas. Pengujian jamur Trichoderma spp. sebagai PGPF (Plant Growth Promoting Fungi) menggunakan tanaman indikator timun varietas F1 untuk memperoleh hasil berupa parameter yang menunjukkan kemampuan jamur Trichoderma spp. dalam meningkatkan performa tanaman. Data yang diperoleh dianalisis dengan sidik ragam dan diuji lanjut DMRT (Duncan's Multiple Range Test) pada taraf 5\%. Hasil penelitian menunjukkan semua isolat Trichoderma spp. yang dapat berperan sebagai antagonis terhadap jamur Ganoderma boninense. Pada uji PGPF, terdapat 3 isolat Trichoderma spp. yang menunjukkan performa paling baik sebagai pemacu pertumbuhan tanaman yaitu isolat L1, L5 dan L10. Selain itu isolat tersebut juga memiliki daya antagonis yang baik.
\end{abstract}

Kata Kunci : Trichoderma sp., Ganoderma boninense, antagonis, kerapatan spora, viabilitas, PGPF 


\section{PENDAHULUAN}

Salah satu kendala dalam budidaya kelapa sawit adalah penyakit busuk pangkal batang (BPB) yang disebabkan oleh jamur Ganoderma boninense. Penyakit BPB berkembang sangat pesat terutama pada iklim dengan curah hujan tinggi seperti Indonesia sehingga menyebabkan kerugian yang cukup signifikan bagi produksi kelapa sawit. Di beberapa perkebunan di Indonesia, penyakit ini menyebabkan kematian pada kelapa sawit hingga $80 \%$ atau lebih dari populasi kelapa sawit dan hal tersebut menyebabkan penurunan produk kelapa sawit per satuan luas (Susanto, 2011).

Saat ini pengendalian terhadap patogen pada tanaman masih bertumpu pada penggunaan pestisida sintetik, termasuk pengendalian terhadap jamur Ganoderma boninense. Penggunaan pestisida sintetik ini secara terus-menerus telah banyak dilaporkan dapat membahayakan keselamatan hayati termasuk manusia dan keseimbangan ekosistem (Suwahyono, 2009). Pengendalian menggunakan fungisida sintetik akan meninggalkan residu pada tanaman maupun lingkungan (Samways,1981). Selain itu, penambahan fungisida juga dapat menyebabkan resistensi jamur patogen tanaman terhadap fungisida yang digunakan (Semangun, 2007).

Salah satu cara pengendalian terhadap jamur G.boninense adalah menggunakan agens hayati berupa jamur Trichoderma spp. Berbagai laporan menyebutkan bahwa jamur Trichoderma spp. mampu menghambat berbagai jenis patogen tanaman seperti Fusarium (Purnomo, 2006), Rhizoctonia (Andayaningsih, 2002), Phytopthora (Istikorni, 2002), dan juga G. boninense (Susanto, 2002).

Selain sebagai antagonis, jamur Trichoderma spp.juga dilaporkan berperan sebagai pemacu pertumbuhan tanaman atau biasa disebut sebagai Plant Growth Promoting Fungi (PGPF). PGPF merupakan kelompok jamur pemacu pertumbuhan yang menghasilkan hormon pertumbuhan. Selain itu beberapa spesies PGPF dilaporkan mampu berperan sebagai antibiotik yang berfungsi menghambat pertumbuhan patogen disekitar tanaman (Shivana $d k k$., 1996; Worosuryani, 2006).

Di laboratorium Bioteknologi Pertanian Fakultas Pertanian Universitas Lampung terdapat isolat jamur Trichoderma spp. yang berasal dari Indonesian Culture Collection (InaCC), biotrop dan koleksi Laboratorium Bioteknologi Pertanian FP Unila. Isolatisolat tersebut belum diketahui kemampuannya dalam menghambat jamur G. boninense dan kemampuannya sebagai PGPF. Untuk itu, perlu dilakukan pengujian terhadap kemampuan isolat jamur Trichoderma spp. tersebut sebagai antagonis G. boninense dan PGPF.

\section{BAHAN DAN METODE}

Penelitian ini dilaksanakan pada bulan Februari - Juli 2016. Pengujian kemampuan jamur Trichoderma spp. sebagai PGPF dilaksanakan di rumah kaca Fakultas Pertanian Universitas Lampung. Uji antagonisme jamur Trichoderma spp. terhadap Ganoderma spp. dilakukan di Laboratorium Bioteknologi Pertanian, Fakultas Pertanian, Universitas Lampung.

Percobaan ini disusun menggunakan Rancangan 
Acak Lengkap (RAL) dengan 12 perlakuan dan 4 ulangan. Perlakuan dalam penelitian ini merupakan 12 isolat jamur Trichoderma spp. yang berasal dari koleksi Laboratorium Bioteknologi Pertanian FP Unila, Indonesian Culture Collection (InaCC) dan Biotrop. Pengujian meliputi uji pertumbuhan, kemampuan antagonisme kerapatan spora dan viabilitas spora dan uji antagonis yang dilakukan secara in vitro. Hasil seleksi dari beberapa isolat tersebut akan digunakan untuk pengujian selanjutnya yaitu uji PGPF di rumah kaca Fakultas Pertanian Universitas Lampung. Hasil pengamatan dianalisis ragam dan apabila terdapat perbedaan yang nyata akan dilanjutkan dengan uji DMRT (Duncan's MultipleRange Test) pada taraf $5 \%$.

Penyiapan Media. Media yang digunakan untuk pengujian secara in-vitro adalah PDA (Potato Dextrose Agar). Bahan-bahan yang digunakan adalah isolat jamur Trichoderma spp. dari: koleksi laboratorium Bioteknologi Proteksi Tanaman Jurusan Agroteknologi Fakultas Pertanian Unila; isolat Trichoderma yang diisolasi dari asosiasi dengan tubuh buah Ganoderma boninense (T.G); isolat Trichoderma Indonesian culture collection (InaCC) LIPI;isolat Trichoderma spp. Seameo Biotrop, isolat tubuh buah jamur Ganoderma boninense, kentang, agar,Dextrose, alkohol 70\%, air steril, aquades, dan asam laktat.

\section{Pengujian Kemampuan Tumbuh isolat}

Trichoderma sp. Tahapan ini dilakukan untuk mengetahui kecepatan tumbuh masing- masing isolat yang diuji. Satu bor gabus biakan murni masing-masing isolat jamur Trichoderma spp. yang berumur 4 hari diletakkan di tengah cawan petri yang berisi media PDA. Pengamatan dilakukan setiap hari terhadap diameter koloni jamur secara vertikal dan horisontal. Diameter koloni yang digunakan merupakan rerata hasil dua kali pengukuran diameter.

Pengujian Kerapatan Spora. Kemampuan isolat untuk memproduksi spora diamati dengan cara menambahkan $10 \mathrm{ml}$ air steril pada cawan petri yang berisi biakan murni jamur Trichoderma spp. yang berumur 21 hari. Spora jamur dipanen dengan cara mengeruk secara hati-hati permukaan koloni jamur dengan drigalski agar miselia dan media tidak terikut. Setelah semua spora Trichoderma spp. terlepas, suspensi spora dimasukkan ke dalam tabung reaksi dan dihomogenkan menggunakan rotamixer. Setelah suspensi homogen, diambil sebanyak $1 \mathrm{ml}$ selanjutnya diteteskan pada haemocytometer dan ditutup dengan kaca obyek hingga suspensi mengalir ke bawah kaca obyek dan mengisi ruang hitung. Pengamatan dilakukan dengan menghitung jumlah spora dalam lima sampel kotak sedang dibawah mikroskop dan dihitung rataratanya (Gambar 1).

Kerapatan spora dihitung menggunakan rumus (Ramli, 2004):

\section{$\underline{\text { Rata-rata jumlah spora } \mathrm{d} \times 10^{6}}$ Jumlah spora}

$$
80 \times 0,25
$$

Keterangan :

$\mathrm{d} \quad=$ tingkat pengenceran

$10^{6}=$ konstanta

$0,25=$ konstanta

$80=$ jumlah kotak kecil/kotak yang diamati 


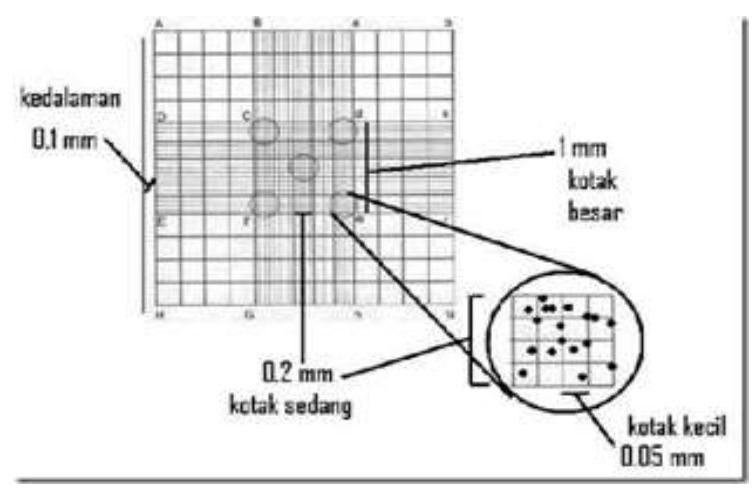

Gambar 1. Haemocytometer

Pengujian viabilitas spora. Uji viabilitas spora dilakukan dengan mengambil suspensi jamur Trichoderma spp. yaitu suspensi yang sama dengan yang digunakan untuk pengukuran kerapatan spora. Suspensi tersebut (masing-masing isolat) diteteskan menggunakan pipet tetes pada media PDA di 3 titik yang berbeda masing masing 1 tetes untuk tiap titik (Gambar 2). Selanjutnya suspensi diamati dibawah mikroskop yang sebelumnya telah diinkubasi selama 12 jam. Pengamatan dilakukan terhadap jumlah spora yang berkecambah dan yang tidak berkecambah. Persentase daya kecambah jamur Trichoderma spp. dihitung menggunakan rumus (Tarman, 2006):

$$
\mathrm{P}=\frac{\text { Spora yang berkecambah }}{\text { Spora seluruhnya }} \times 100 \%
$$

Pengujian Antagonis. Uji antagonisme dilakukan pada media Potato Dextrose Agar (PDA) dalam cawan petri dengan menggunakan metode $d u a l$ culture (Mahadtanapuk, $d k k$., 2007). Satu potongan bor gabus (diameter $0,8 \mathrm{~cm}$ ) biakan murni jamur Ganoderma boninense diletakkan pada sebuah titik

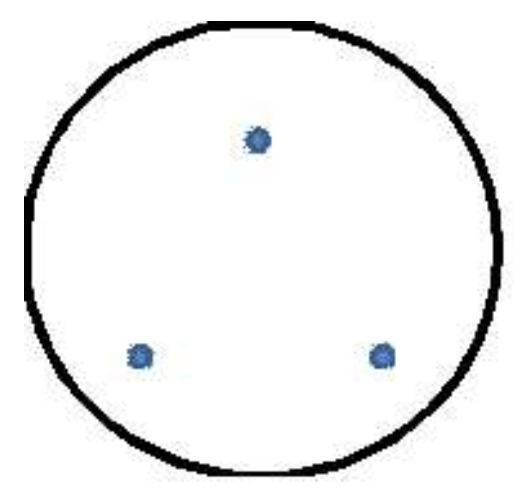

Gambar 2. Titik penetesan suspensi Trichoderma spp. pada media PDA

dengan jarak $3 \mathrm{~cm}$ dari tepi cawan petri, sedangkan dari tepi yang lain dengan jarak yang sama diletakkan satu potongan bor gabus (diameter $0,8 \mathrm{~cm}$ ) biakan murni Trichoderma spp. (Gambar 3). Inkubasi dilakukan di suhu ruang selama 3-4 hari (Prasetyo, dkk., 2009). Pengamatan dilakukan setiap hari terhadap jari-jari koloni G. boninense yang berlawanan dan jari-jari koloni yang menuju arah jamur Trichoderma spp.

Pengamatan dilakukan setiap hari terhadap jari-jari koloni G. boninense yang berlawanan dan jarijari koloni yang menuju arah jamur Trichoderma spp. Persentase penghambatannya diukur menggunakan rumus (Prasetyo dkk., 2009) :

Persentase daerah penghambatan $=$

$$
\frac{\mathrm{r} 1-r 2}{r 1} \times 100 \%
$$

\section{Uji Kemampuan Trichoderma spp. sebagai}

PGPF. Media yang digunakan pada pengujian PGPF ini adalah campuran pasir dan pupuk kandang dengan perbandingan 1: 1. Media selanjutnya disterilisasi dengan menggunakan autoklaf hingga suhu $121^{\circ} \mathrm{C}$ pada 


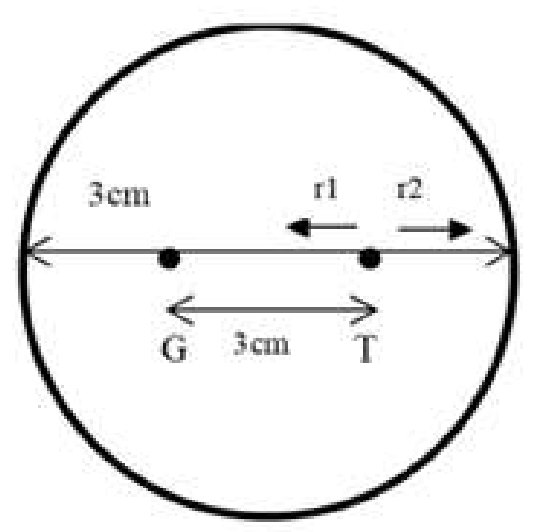

Gambar 3. Cara peletakan inokulum G. Boninense dan Trichoderma harzianum.

Keterangan :

r1 = Jari-jari koloni Ganoderma boninense yang berlawanan arah dengan jamur Trichoderma spp.

r2 = Jari-jari koloni Ganoderma boninense yang menuju arah jamur Trichoderma spp.

Tabel 1. Isolat Trichoderma spp. yang digunakan dalam pengujian antagonis terhadap Ganoderma boninense

\begin{tabular}{ccc}
\hline Kode Isolat & Asal Isolat & Tahun Isolat \\
\hline N1 & Nanas & 2015 \\
N3 & Nanas & 2015 \\
N15 & Nanas & 2015 \\
N24 & Nanas & 2015 \\
L1 & InaCC & - \\
L5 & InaCC & - \\
L9 & InaCC & - \\
L10 & InaCC & - \\
S1 & Seameo Biotrop & - \\
S2 & Seameo Biotrop & - \\
S3 & Tubuh buah Ganoderma & 2016 \\
S4 & Tubuh buah Ganoderma & 2016 \\
\hline
\end{tabular}

tekanan 1 atm selama 15 menit. Media yang sudah steril kemudian dipindahkan kedalam polybag ukuran 0,5 Kg. Masing masing polybag diisi media kurang lebih 500 gram dan diletakkan di rumah kaca Fakultas Pertanian Unila.

Penyiapan Tanaman Indikator. Tanaman indikator yang digunakan dalam uji PGPF adalah tanaman mentimun. Benih mentimun varietas Mercy
(F1) didisinfeksi dengan etanol 70\% dan sodium hypochlorite $2 \%$, kemudian disemai didalam cawan petri menggunakan lapisan kertas merang.

\section{Penyiapan Media Beras untuk}

Perbanyakan Isolat. Media yang digunakan untuk memperbanyak isolat adalah media beras. Beras yang akan digunakan sebagai media dicuci dan ditiriskan. Setelah ditiriskan, dikukus selama 5 menit dan 
dimasukkan ke dalam 12 plastik tahan panas, kemudian di masukkan ke dalam autoklaf. Masing-masing plastik berisi 100 gram beras.

Penyiapan Isolat Jamur Trichoderma spp. Masing-masing isolat jamur yang akan diuji diremajakan pada media PDA selama 3 hari. Setelah berumur 3 hari, satu potong bor gabus biakan murni dengan diameter $\pm 3 \mathrm{~mm}$ dipindahkan ke dalam kantong plastik yang berisi media beras $(100 \mathrm{~g})$ steril dan diikat. Kultur diinkubasi selama 10 hari pada suhu kamar (Worosuryani, 2006).
Aplikasi. Sebanyak 10 gram media beras yang telah diinokulasikan dengan Trichoderma spp. dicampurke dalam media tanam yang telah dimasukkan ke dalam polybag. Bibit mentimun yang berumur 2 hari kemudian dipindahtanamkan ke dalam yang telah diinokulasi dengan masing masing jamur Trichoderma sp. yang akan diuji. Pengamatan dilakukan 2 hari sekali selama 21 hari terhadap tinggi tanaman, jumlah daun dan kehijauan daun (menggunakan chlorophylmeter). Kenampakan akar, panjang akar, berat basah dan kering akar (root) serta berangkasan (shoot) diamati pada akhir pengamatan.
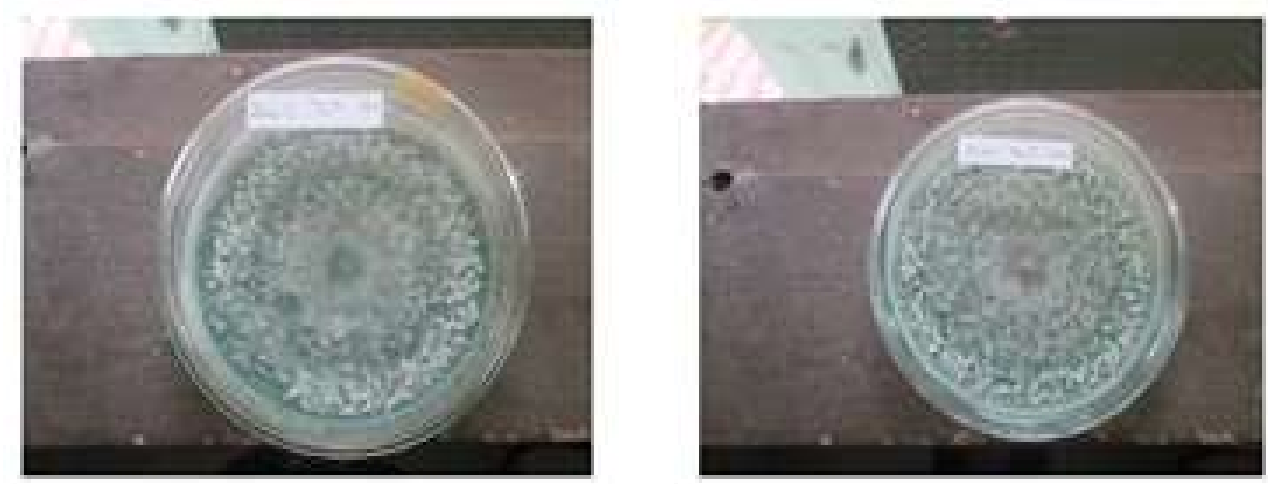

Gambar 4. Kenampakan diameter spora isolat N1 (1) dan isolat N3 (2)
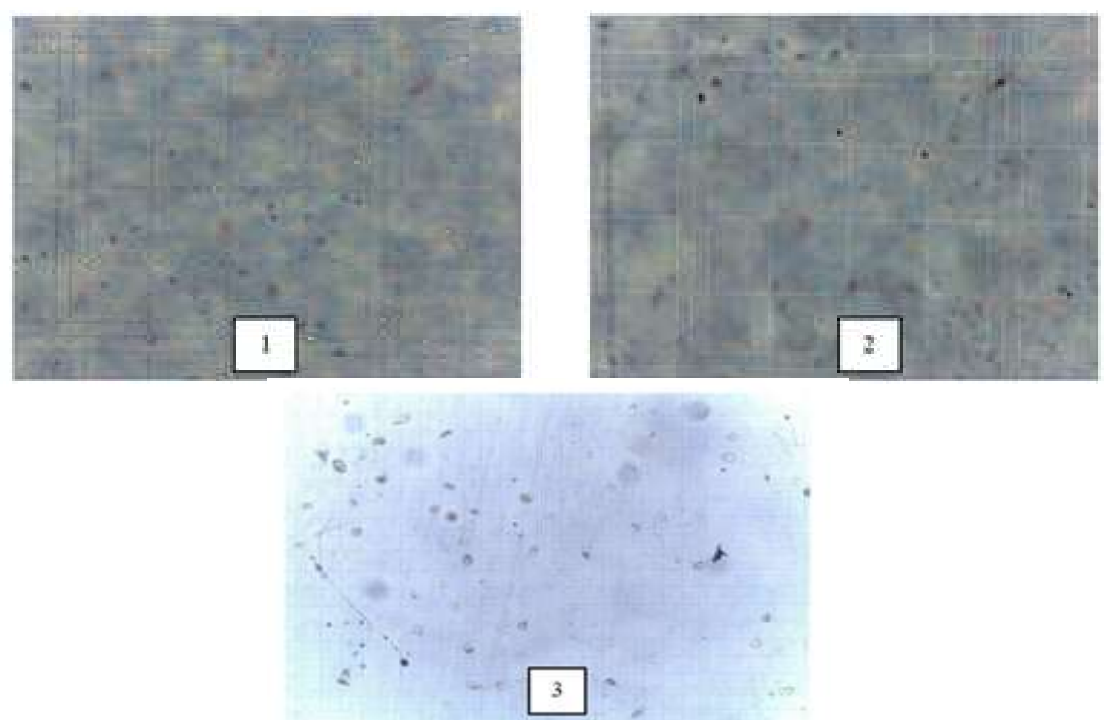

Gambar 5. Kerapatan spora isolat L1 (1), isolat L5 (2) dan isolat S1 (3). 
Tabel 2. Diameter pertumbuhan koloni Trichoderma spp. 4 hari setelah inokulasi

\begin{tabular}{cc}
\hline Isolat & Diameter $(\mathrm{cm})$ \\
\hline N1 & $9 \mathrm{a}$ \\
N3 & $9 \mathrm{a}$ \\
N15 & $9 \mathrm{a}$ \\
N24 & $9 \mathrm{a}$ \\
L1 & $8,8 \mathrm{~b}$ \\
L5 & $8,4 \mathrm{~d}$ \\
L9 & $8,5 \mathrm{c}$ \\
L10 & $8,4 \mathrm{~d}$ \\
S1 & $9 \mathrm{a}$ \\
S2 & $9 \mathrm{a}$ \\
S3 & $9 \mathrm{a}$ \\
S4 & $9 \mathrm{a}$ \\
\hline
\end{tabular}

Pengumpulan dan Analisis Data. Data diameter koloni, produksi spora, viabilitas spora, tinggi tanaman, jumlah daun, kehijauan daun, panjang akar, berat basah dan kering akar dan brangkasan dianalisis ragam menggunakan ANOVA, dan apabila terdapat beda nyata antar perlakuan dilanjutkan dengan uji DMRT dengan taraf nyata 5\%.

\section{HASIL DAN PEMBAHASAN}

\section{Diameter Koloni Isolat Jamur}

Trichoderma spp. Semua isolat yang diuji menunjukkan pertumbuhan yang hampir sama pada hari ke-4 setelah inokulasi. Sebanyak 1 isolat (L1) memiliki diameter 8,8 cm, 2 isolat (L5 dan L10) mempunyai diameter koloni 8,4 cm, sebanyak 1 isolat(L9) memiliki diameter koloni $8,5 \mathrm{~cm}$, sebanyak 8 isolat $(\mathrm{N} 1, \mathrm{~N} 3$, N15, N24, S1, S2, S3 dan S4) memiliki diameter koloni $9 \mathrm{~cm}$ (Tabel 2). Kenampakan diameter isolat dapat dilihat pada Gambar 4.

Kerapatan Spora. Dari setiap isolasi, kerapatan spora tertinggi diperoleh sebesar 31,25 X $10^{8}(\mathrm{~L} 1)$. Sebanyak 1 isolat (S3) memiliki produksi spora sebesar 19,0 x 10 $/ \mathrm{ml}$ dan 1 isolat(N24) dengan produksi spora sebesar 18,5 × 108/ml. Selain itu juga terdapat isolat dengan produksi spora sebesar 13,0 $\mathrm{x}$ $10^{8} / \mathrm{ml}$ (L5). Sebanyak 7 isolat (L9, L10, N1, N3, S1, S2, dan S4) memiliki produksi spora pada kisaran 3,0-12,0 x 108/ml (Tabel 3). Kerapatan spora yang diperoleh pada umur 21 hari setelah inokulasi dapat dilihat pada Gambar 5.

Viabilitas Spora. Viabilitas spora yang diproduksi oleh masing masing isolat berkisar antara $91,5-100 \%$. Sebanyak 2 isolat N24 dan N3 berturutturut memiliki viabilitas spora 91,5\% dan 3,7\%. Sedangkan sebanyak 7 isolat (L9, S2, S3,L5, S1, N15, dan L10) memiliki viabilitas antara 92,1 - 98\% dan sebanyak 3 isolat (N1,L1 dan S4) memiliki viabilitas spora sebesar 100\% (Tabel 4). Gambar mikroskopis viabilitas spora dapat dilihat pada gambar 6. 

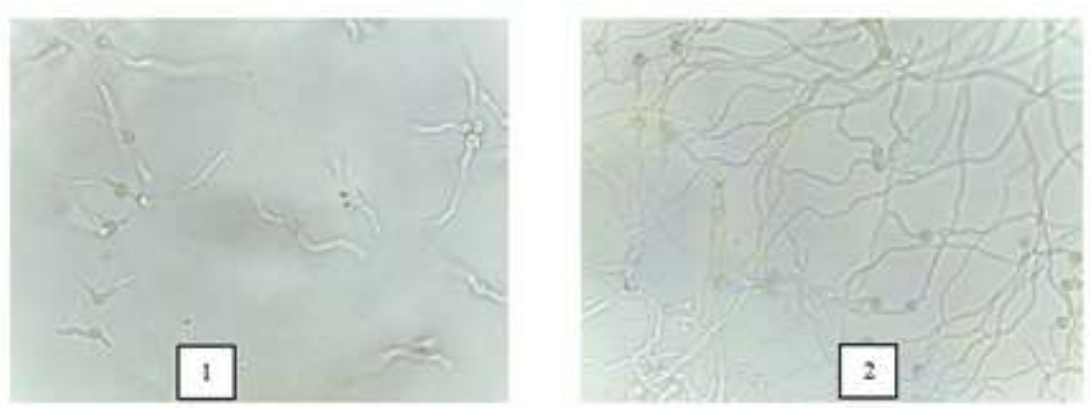

Gambar 6. Gambar viabilitas spora isolat Trichoderma spp. belum berkecambah (1) dan isolat Trichoderma spp. yang sudah berkecambah (2).

Tabel 3. Kerapatan spora isolat Trichoderma spp. pada umur 21 hari setelah inokulasi

\begin{tabular}{cc}
\hline Isolat & Kerapatan spora $\left(\times 10^{8}\right)$ \\
\hline N1 & $9,00 \mathrm{def}$ \\
N3 & $6,75 \mathrm{efg}$ \\
N15 & $17,25 \mathrm{bc}$ \\
N24 & $18,50 \mathrm{~b}$ \\
L1 & $31,25 \mathrm{a}$ \\
L5 & $13,00 \mathrm{~cd}$ \\
L9 & $10,75 \mathrm{def}$ \\
L10 & $11,75 \mathrm{cde}$ \\
S1 & $3,00 \mathrm{fg}$ \\
S2 & $5,75 \mathrm{fg}$ \\
S3 & $19,00 \mathrm{~b}$ \\
S4 & $12,00 \mathrm{cde}$ \\
\hline
\end{tabular}

\section{Persentase Penghambatan Isolat}

\section{Trichoderma spp.terhadap Ganoderma}

boninense. Persentase penghambatan masing-masing isolat Trichoderma spp. terhadap G. boninense memberikan pengaruh yang berbeda nyata yaitu untuk 4 isolat (N3, L1, L5 dan L10) memiliki persentase penghambatan yang lebih tinggi dibandingkan 8 isolat (N1, N15, N24, L9, S1, S2, S3 dan S4) lainnya. Sedangkan terdapat 1 isolat dengan persentase penghambatan terkecil dari semua isolat yaitu isolat $\mathrm{S} 2$ (Tabel 5). Kenampakan penghambatan isolat
Trichoderma spp. terhadap Ganoderma boninense dapat dilihat pada Gambar 7.

\section{Kemampuan sebagai Plant Growth}

Promoting Fungi (PGPF). Kemampuan isolat Trichoderma spp. sebagai PGPF ditentukan dari hasil pengukuran beberapa parameter. Parameter-parameter tersebut antara lain tinggi tanaman, panjang akar, berat basah tajuk dan akar, berat kering tajuk dan akar. Hasil pengamatan menunjukkan bahwa tidak semua isolat mampu memacu pertumbuhan tanaman. Hal tersebut terlihat dari hasil aplikasi beberapa isolat yang ternyata 
Tabel 4. Viabilitas spora masing-masing isolat pada umur 21 hari setelah inokulasi

\begin{tabular}{cc}
\hline Isolat & Viabilitas Spora (\%) \\
\hline N1 & $97,7 \mathrm{ab}$ \\
N3 & $97,8 \mathrm{ab}$ \\
N15 & $95,7 \mathrm{ab}$ \\
N24 & $91,5 \mathrm{~b}$ \\
L1 & $100,0 \mathrm{a}$ \\
L5 & $94,4 \mathrm{ab}$ \\
L9 & $92,1 \mathrm{ab}$ \\
L10 & $98,0 \mathrm{ab}$ \\
S1 & $95,0 \mathrm{ab}$ \\
S2 & $93,3 \mathrm{ab}$ \\
S3 & $93,8 \mathrm{ab}$ \\
S4 & $100,0 \mathrm{a}$ \\
\hline
\end{tabular}

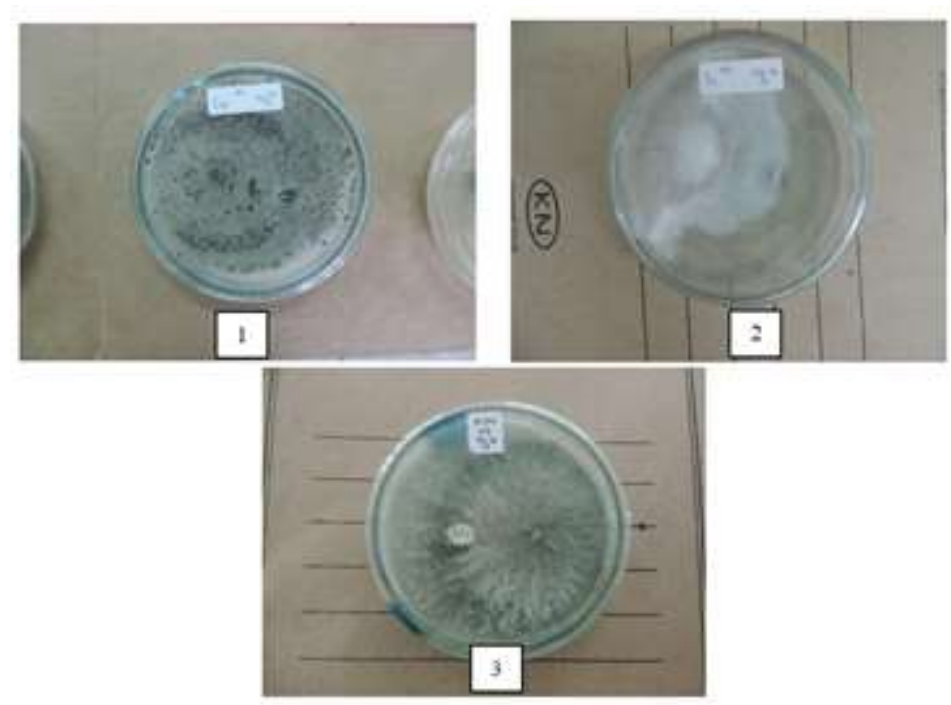

Gambar 7. Kenampakan penghambatan isolat Trichoderm a spp. terhadap Ganoderma boninense: $100 \%$ (1), 20,8\% (2) dan 80,2\% (3).

menghasilkan tinggi tanaman yang lebih rendah dibandingkan dengan kontrol.

Tinggi tanaman. Hasil pengukuran menunjukkan bahwa terdapat 8 isolat $(\mathrm{N} 1, \mathrm{~N} 3, \mathrm{~N} 15$, L9, S1, S2, S3 dan S4) memiliki hasil yang tidak berbeda nyata dengan kontrol dan sebanyak 4 isolat (N24, L1, L5 dan L10) menunjukkan hasil yang berbeda nyata yaitu lebih tinggi dari kontrol (Tabel 6).
Panjang akar. Sebanyak 12 isolat (N1, N3, N15, N24, L1, L5, L9, L10, S1, S2, S3 dan S4) menghasilkan panjang akar yang tidak berbeda nyata dengan kontrol, sedangkan untuk isolat S3 memiliki hasil yang berbeda nyata dengan isolat L5 dimana isolat L5 memiliki akar yang lebih panjang (Tabel 6).

Bobot basah tajuk dan akar. Untuk bobot basah tajuk, sebanyak 7 isolat $(\mathrm{N} 1, \mathrm{~N} 3, \mathrm{~N} 15, \mathrm{~S} 1, \mathrm{~S} 2$, 
Tabel 6. Hasil pengukuran parameter untuk penentuan sebagai Plant Growth Promoting Fungi (PGPF)

\begin{tabular}{cccccccc}
\hline Kode & $\begin{array}{c}\text { Tinggi } \\
\text { Tanaman } \\
(\mathrm{cm})\end{array}$ & $\begin{array}{c}\text { Panjang } \\
\text { Akar }(\mathrm{cm})\end{array}$ & $\begin{array}{c}\text { Bobot } \\
\text { Basah Tajuk } \\
(\mathrm{g})\end{array}$ & $\begin{array}{c}\text { Bobot } \\
\text { Basah Akar } \\
(\mathrm{g})\end{array}$ & $\begin{array}{c}\text { Bobot } \\
\text { Kering Tajuk } \\
(\mathrm{g})\end{array}$ & $\begin{array}{c}\text { Bobot } \\
\text { Kering Akar } \\
(\mathrm{g})\end{array}$ & $\begin{array}{c}\text { Hijau Daun } \\
(\mathrm{CCI})\end{array}$ \\
\hline $\mathrm{N} 1$ & $37,8 \mathrm{~d}$ & $16,8 \mathrm{ab}$ & $6,2 \mathrm{~d}$ & $0,5 \mathrm{bc}$ & $1,2 \mathrm{~cd}$ & $0,5 \mathrm{bc}$ & $13,8 \mathrm{a}$ \\
$\mathrm{N} 3$ & $50,8 \mathrm{~cd}$ & $17,6 \mathrm{ab}$ & $7,8 \mathrm{~d}$ & $0,6 \mathrm{~b}$ & $1,4 \mathrm{~cd}$ & $0,5 \mathrm{bc}$ & $15,1 \mathrm{a}$ \\
$\mathrm{N} 15$ & $52,5 \mathrm{bcd}$ & $18,6 \mathrm{ab}$ & $9,9 \mathrm{bcd}$ & $0,5 \mathrm{bc}$ & $2,3 \mathrm{ab}$ & $0,4 \mathrm{bcd}$ & $13,6 \mathrm{a}$ \\
$\mathrm{N} 24$ & $72,5 \mathrm{ab}$ & $19,0 \mathrm{ab}$ & $13,5 \mathrm{abc}$ & $0,4 \mathrm{bc}$ & $1,4 \mathrm{~cd}$ & $0,3 \mathrm{~cd}$ & $14,7 \mathrm{a}$ \\
$\mathrm{L} 1$ & $73,5 \mathrm{ab}$ & $17,9 \mathrm{ab}$ & $14,4 \mathrm{ab}$ & $0,2 \mathrm{c}$ & $2,5 \mathrm{ab}$ & $0,5 \mathrm{bc}$ & $14,7 \mathrm{a}$ \\
$\mathrm{L} 5$ & $83,3 \mathrm{a}$ & $23,0 \mathrm{a}$ & $17,1 \mathrm{a}$ & $0,6 \mathrm{~b}$ & $2,3 \mathrm{ab}$ & $0,2 \mathrm{~d}$ & $12,3 \mathrm{ab}$ \\
$\mathrm{L} 9$ & $64,5 \mathrm{abc}$ & $21,5 \mathrm{ab}$ & $13,9 \mathrm{ab}$ & $0,6 \mathrm{~b}$ & $0,6 \mathrm{de}$ & $0,3 \mathrm{~cd}$ & $13,7 \mathrm{a}$ \\
L10 & $79,3 \mathrm{a}$ & $18,5 \mathrm{ab}$ & $14,6 \mathrm{ab}$ & $0,9 \mathrm{a}$ & $2,7 \mathrm{a}$ & $0,6 \mathrm{ab}$ & $13 \mathrm{a}$ \\
$\mathrm{S} 1$ & $53,0 \mathrm{bcd}$ & $18,1 \mathrm{ab}$ & $10,0 \mathrm{bcd}$ & $0,5 \mathrm{bc}$ & $1,8 \mathrm{bc}$ & $0,4 \mathrm{~cd}$ & $13,4 \mathrm{a}$ \\
$\mathrm{S} 2$ & $56,8 \mathrm{bcd}$ & $19,0 \mathrm{ab}$ & $10,5 \mathrm{bcd}$ & $0,5 \mathrm{bc}$ & $2,3 \mathrm{ab}$ & $0,3 \mathrm{~cd}$ & $12,8 \mathrm{a}$ \\
$\mathrm{S} 3$ & $50,0 \mathrm{~cd}$ & $15,3 \mathrm{~b}$ & $8,2 \mathrm{~cd}$ & $0,6 \mathrm{~b}$ & $0,3 \mathrm{e}$ & $0,4 \mathrm{bcd}$ & $9,0 \mathrm{c}$ \\
$\mathrm{S} 4$ & $62,3 \mathrm{abc}$ & $19,5 \mathrm{ab}$ & $11,3 \mathrm{bcd}$ & $0,5 \mathrm{bc}$ & $2,8 \mathrm{a}$ & $0,8 \mathrm{a}$ & $9,7 \mathrm{bc}$ \\
$\mathrm{K} *$ & $48,0 \mathrm{~cd}$ & $17,6 \mathrm{ab}$ & $6,0 \mathrm{~d}$ & $0,6 \mathrm{~b}$ & $1,2 \mathrm{~cd}$ & $0,3 \mathrm{~cd}$ & $6,8 \mathrm{c}$ \\
\hline
\end{tabular}
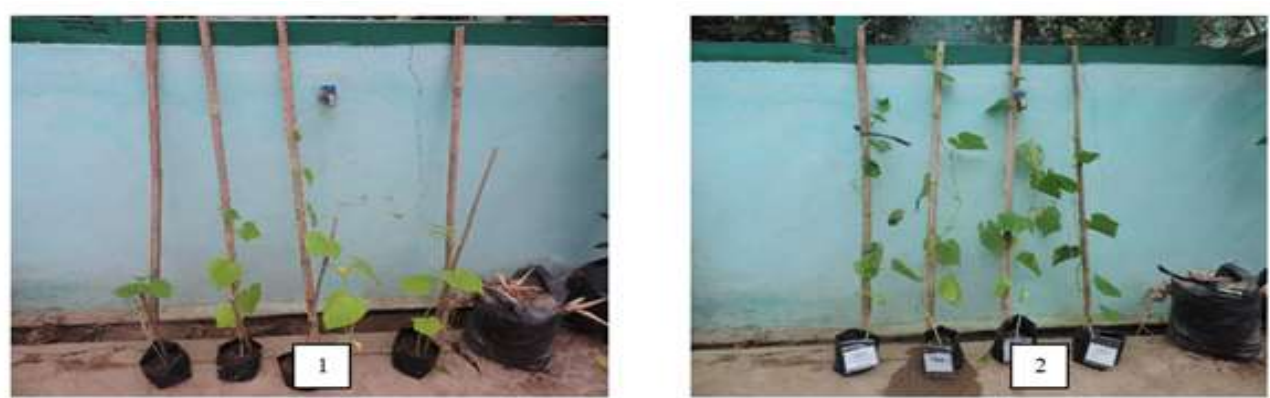

Gambar 8. Kenampakan tinggi tanaman hasil uji PGPF. Tanaman kontrol (1) dan tanaman yang diberi perlakuan L1 (2).

S3 dan S4) menghasilkan bobot yang tidak berbeda nyata dengan kontrol dan 5 isolat (N24, L1, L5, L9 dan L10 ) menghasilkan bobot yang berbeda nyata yaitu lebih tinggi dari kontrol. Untuk parameter bobot basah akar, hanya ada 2 isolat (L1 dan L10) menghasilkan bobot basah akar yang berbeda nyata dengan kontrol yaitu L10 lebih tinggi daripada kontrol dan L1 lebih rendah daripada kontrol (Tabel 6).

Bobot kering tajuk dan akar. Pada parameter bobot kering tajuk sebanyak 7 isolat (N15, L1, L5,
L10, S2, S3 dan S4) menghasilkan bobot kering tajuk yang berbeda nyata dengan kontrol, dimana untuk isolat S3 memiliki bobot yang lebih rendah dibandingkan kontrol. Pada parameter bobot kering akar, sebanyak 2 isolat (L10 dan S4) menghasilkan bobot kering akar yang berbeda nyata yaitu lebih tinggi dibandingkan kontrol (Tabel 6).

Isolat Jamur Trichoderma spp. yang berperan sebagai Antagonis dan PGPF Dalam penelitian ini, isolat Trichoderma spp. dikatakan 

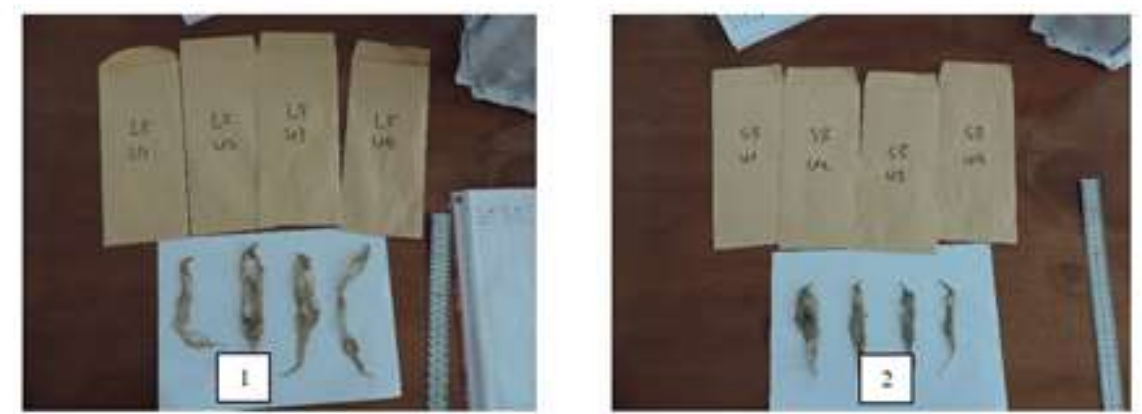

Gambar 9. Kenampakan panjang akar tanaman hasil uji PGPF. Tanaman yang diberi perlakuan L5 (1) dan tanaman yang diberi perlakuan S3 (2)

berperan sebagai antagonis apabila isolat tersebut memiliki persentase penghambatan $>50 \%$. Isolat Trichoderma spp. dikatakan berperan sebagai PGPF apabila isolat tersebut memberikan hasil yang lebih baik daripada kontrol untuk semua parameter yang digunakan. Hasil analisis menunjukkan bahwa terdapat 11 isolat yang berperan sebagai antagonis dan 3 isolat yang berperan sebagai PGPF (Tabel 7).

\section{KESIMPULAN}

Dari 12 isolat jamur Trichoderma spp. koleksi Laboratorium Bioteknologi Pertanian FP Unila, semua isolat dapat berperan sebagai antagonis jamur $G$. boninense. Selain itu terdapat 3 isolat yang mampu berperan sebagai antagonis dan PGPF. Saran dari penelitian ini adalah perlu dilakukan aplikasi jamur Trichoderma spp. di bibit kelapa sawit untuk menghambat pertumbuhan Ganoderma boninense.

\section{DAFTAR PUSTAKA}

Andayaningsih, P. 2002. Kemampuan Trichoderma sp. dalam Pengendalian Patogenitas Rhizoctonia solani pada Tanaman Kedelai. Jurnal Bionatura 4(1): 1-8.

Istikorni, Y. 2002. Pengendalian Penyakit Tumbuhan Secara Hayati yang Ekologis dan Berkelanjutan. Makalah falsafah sains. Institut Pertanian Bogor.

Mahadtanapuk, S.M., Sanguansermsri, R.W., Cutler, V., Sardsud \&Anuntalabhochai, S. 2007. Control of Anthracnose Caused by Colletotrichum musae on Curcuma alismatifolia Gagnep. Using Antagonistic Bacillus spp. Journal of Agricultural and Biological Sciences 2(2) : 54-61.

Prasetyo, J., Efri, \& Suharjo, R. 2009. Seleksi dan uji Antagonisme Trichoderma spp. Isolat Tahan Fungisida Nabati terhadap Pertumbuhan Phytophtora capsici. Jurnal HPT Tropika 9(1) : 58-66.

Purnomo, B. 2006. Seleksi Jamur Rizosfer NonPatogenik untuk Pengendalian Penyakit Layu Fusarium pada Tanaman Jahe di Bengkulu. Jurnal Ilmu-Ilmu Pertanian Indonesia 8(1): 611. 
Ramli, N. 2004. Petunjuk Teknis pada Berbagai Kegiatan Laboratorium Lapangan. Balai Pengembangan Proteksi Tanaman Perkebunan Sumatera Utara. Medan.

Samways, M. J. 1981. Biological Control of Pest and Weeds. Edward Arnold. London.

Semangun, H. 2007. Penyakit-Penyakit Tanaman Hortikultura di Indonesia. Gajah Mada University Press. Yogyakarta.

Shivana, M. B., Meer, M. S., Kageyama, K., \& Hyakumachi, M. 1994. Sterile Fungi from Zoysiagrass Rhizosphere as Plant Growth Promoters in Spring Wheat. Journal of Microbiology 40(8): $637-644$.

Shivana, M. B., Meera, M.S. \& Hyakumachi, M. 1996. Role of Root Colonization Ability of Plant Growth Promoting Fungi in the Suppression of take-All and Common Root Rot of Wheat. Research Paper Crop Protection 15(6): 497504.
Susanto A. 2002. Kajian pengendalian hayati Ganoderma boninense Pat, penyebab penyakit busuk pangkal batang kelapa sawit. [Disertasi]. Institut Pertanian Bogor. Bogor.

Susanto, A. 2011. Penyakit Busuk Pangkal Batang Ganoderma boinense pat. Informasi Organisme Pengganggu Tanaman. Pusat Penelitian Kelapa Sawit. Medan.

Suwahyono, U. 2009. Biopestisida. PT. Niaga Swadaya. Jakarta.

Tarman, P.E. 2006. Pengaruh Lama Masa Inkubasi Jamur Antagonis Trichoderma harzianum terhadap Daya Hambat Perkembangan Jamur Patogen Fusarium oxysporum Penyebab Penyakit Layu Tanaman Tomat. Jurnal Unbar 1(1): 1-8.

Worosuryani, C., Priyatmojo, A. \& Wibowo, A. 2006. Uji Kemampuan Jamur yang diisolasi dari Lahan Pasir Sebagai PGPF (Plant Growth Promoting Fungi). Jurnal Agrosains 19(2): 179 192. 